\title{
Numerical Investigation of the Short-Term Mechanical Response of Buried Profiled Thermoplastic Pipes with Different Diameters to External Loads
}

\author{
Yongti Shan $\mathbb{D}^{1},{ }^{1,2}$ Guijun Shi $\mathbb{D}^{1,2}$ Qunfang Hu $\mathbb{D}^{\mathrm{D}},{ }^{3}$ Yunhui Zhang $\mathbb{D}^{4},{ }^{4}$ and Fu Wang $\mathbb{D}^{4}$ \\ ${ }^{1}$ CCCC First Highway Consultants CO.,Ltd., Xian 710000, China \\ ${ }^{2}$ Xi'an Zhongjiao Environmental Engineering Co.,Ltd, Xian 710075, China \\ ${ }^{3}$ Shanghai Institute of Disaster Prevention and Relief, Tongji University, Shanghai 200092, China \\ ${ }^{4}$ College of Water Conservancy and Environmental Engineering, Zhengzhou University, Zhengzhou 450001, China
}

Correspondence should be addressed to Qunfang Hu; huqunf@tongji.edu.cn

Received 28 September 2020; Revised 27 March 2021; Accepted 12 May 2021; Published 24 May 2021

Academic Editor: R. Emre Erkmen

Copyright (C) 2021 Yongti Shan et al. This is an open access article distributed under the Creative Commons Attribution License, which permits unrestricted use, distribution, and reproduction in any medium, provided the original work is properly cited.

High-density polyethylene (HDPE) double-wall corrugated pipe is a flexible buried pipe widely used in municipal drainage, and its deformation is affected by the compactness of the surrounding soil. This paper uses the ABAQUS to establish a three-dimensional pipe-soil model of double-wall corrugated pipes, and the mechanical response behavior of corrugated pipes with different nominal diameters subject to external loads is studied. The results show that the strain distribution characteristics for pipes with different diameters are very similar, and the circumferential strain value at critical positions of the pipe is proportional to its nominal diameter. Under poor backfill conditions, small-diameter pipelines are more prone to damage caused by strain concentration, while large-diameter pipelines may be damaged due to local bending.

\section{Introduction}

Economic development has accelerated the construction of urban infrastructure, and the scale of municipal drainage pipelines is also expanding. Municipal drainage pipelines can be roughly divided into two categories according to pipe stiffness: rigid pipeline and flexible pipeline. With different mechanical properties, these two kinds of pipelines have different responses to external loads and failure modes. External load acts on the ground, and the combined action of external load and upper Earth pressure causes the rigid pipeline to deform. The weak parts of the pipeline, such as joints, are prone to fracture or misalignment, resulting in pipeline leakage. For flexible pipes, the deformation is determined by the pipe stiffness and the state of the surrounding soil [1]. The dependence of the deformation of the flexible pipeline on the soil stiffness makes the pipeline installation a demanding task, and the pipeline is often damaged by large deformation due to poor backfill conditions [2]. Currently, the plastic pipeline is in use in municipal drainage because of its advantages, such as lightweight, corrosion resistance, good hydraulic performance, and economy [3]. High-density polyethylene (HDPE) double-wall corrugated pipe is a buried plastic pipe. Its unique sectional structure (corrugated exterior wall, straight interior wall) makes its stiffness much higher than that of the straight-wall pipelines with the same wall thickness, so it finds universal application in municipal drainage.

HDPE double-wall corrugated pipe, as a typical flexible buried pipe, has lower stiffness than the surrounding soil. When a load is applied to the ground, the downward displacement of the soil on the pipe side is less than that of soil directly above the pipeline. The soil above the pipelines is subjected to upward friction from the surrounding soil, and the actual Earth pressure on the crown of the pipes is less than the weight of the central soil column; this phenomenon is called soil arching [4]. The responses of the flexible pipe to 
the backfill and external loads are discussed using field tests, laboratory tests, and numerical simulations. Researchers investigated the effect of backfill stiffness on pipe deformation, with backfill stiffness being controlled by factors such as backfill material, grade, moisture content, compaction method, and assembly method.

In the 1930s, through the research on the deformation of many buried pipelines, Marston first proposed the "Marston theory" based on the limit equilibrium theory of a rigid body and developed the design theories and methods for different types of buried pipelines [5]. Howard (1990) compared the experimental value with the predicted value of Spangler's equation, and the result showed that the experimental value of the deflection of the polyvinyl chloride (PVC) pipe is much lower than the predicted value when the backfill is loosely compacted [6]. Faragher (1998) used a laboratory test to study the plastic pipeline's axial strain response to the compaction of the backfill during the assembly process when sand or gravel was used as the backfill material [7]. Sargand (2002) carried out a full-scale field test to study the response of plastic pipelines with different installation parameters (backfill material, compaction degree, and cushion thickness) to external loads [8]. By measuring the pressure distribution of the surrounding soil and the deflection deformation state of the HDPE pipes buried in the wellgraded fine sand, Wang et al. (2015) related the ratio of the vertical deformation to horizontal deformation of the pipeline with its buried depth. They put forward a semiempirical formula [9]. Tafreshi and Khalaj (2011) investigated the ground settlement of the backfill and the radial deformation of the HDPE pipe by using repeated loads to simulate vehicle loads in the laboratory and changing parameters like the buried depth, the backfill density, the load size, and the load frequency [10]. Based on the field tests and numerical simulations, Zhou et al. $(2017,2018,2020)$ studied the deformation of buried HDPE pipes during the installation process and pointed out the influence of the compaction degree of the surrounding soil on the deflection deformation of the pipe, and then the feasibility of the use of geosynthetics to reinforce pipes subjected to localized ground subsidence was investigated [11-13]. You et al. (2014) measured the deflection and circumferential strain produced during the installation process of the pipe in the field tests and proposed an empirical formula for predicting the corresponding circumferential strain on HDPE pipes in this process [14]. Kang et al. (2013, 2014) analyzed the maximum and minimum burial depths (cover) allowed for using thermoplastic pipes in highways by evaluating deflection and stress criteria of pipes $[15,16]$. Zhou et al. (2019a, 2019b) presented a series of large-scale model tests aiming to investigate the performance of buried HDPE double-wall corrugated pipes subjected to the localized ground subsidence and fault movement [17, 18]. Talesnick et al. (2011) embedded a pressure sensor in the pipe wall to measure the radial Earth pressure and deflection of the HDPE pipe when the static load acted on the ground surface. The measurement results showed that the radial Earth pressure around the pipe and the pipe deflection are susceptible to the backfill compaction degree [19]. Terzi et al.
(2012) buried HDPE pipes in poorly graded sand with different compaction degrees to measure the strain response of pipe to external loads. The results indicated that when the backfill around the pipe is loose, the maximum strain occurs at the invert of the pipes, and when the backfill is fully compacted, the maximum strain occurs on the crown of the pipes [20]. Brachman et al. (2008) conducted laboratory experiments to compare the effects of compaction methods, backfill materials, and gradation on the deflection, strain, and local bending of special-shaped thermoplastic pipes. They proposed an empirical coefficient based on measured data to simplify the maximum local bending strain calculation in designing these pipes [21]. Mohamedzein and Aghbari (2016) studied through laboratory tests that when the backfill is compacted, the plastic pipe is less affected by the external loads and undergoes a small elastic deformation [22].

With the popularization of finite element analysis software, numerical simulation has been widely used to calculate the deformation of pipelines. Dezfooli et al. (2015a, 2015b) established the FE model and used the three experimental field tests to simulate the deformation of buried steel pipes during staged construction installation $[23,24]$. Dhar et al. (2004) verified that the two-dimensional finite element model could effectively calculate the deflection and circumferential strain in the pipe under external loads through the biaxial pipe laboratory tests and used the two-dimensional finite element analysis to study the distribution of strain in the special-shaped thermoplastic pipes when the backfill was locally loose [25]. Abri and Mohamedzein (2010) formulated a two-dimensional finite element model using ABAQUS for evaluating the deformation of HDPE and PVC pipes with sandy backfill subjected to different degrees of compaction [26]. Noor and Dhar (2003) established a 3D pipe-soil interaction model based on ANSYS and discussed the deflection deformation of the pipe under the traffic loads (simplified as static loads) [27]. By establishing a 3D finite element model, Naeini et al. (2016) analyzed the deformation of the pipe under normal fault motion while considering the influence of the pipe diameter, thickness, buried depth, friction angle, and backfill density on the bending strain of the pipe [28]. Based on a reliable $3 \mathrm{D}$ model of cured-in-place pipes (CIPP), Zhai et al. $(2019,2021 \mathrm{a}, 2021 \mathrm{~b})$ investigated the changes in the mechanical properties of the pipes before and after the repair of carbon-fiber-reinforced polymer (CFRP) layers [29-31].

In summary, the researchers in this field have extensively studied the mechanical response of flexible pipes to external loads and backfill during the assembly and operation processes. However, the mechanical response of HDPE double-wall corrugated pipes with different nominal diameters is not yet well-researched. Therefore, a 3D finite element pipe-soil model was prepared using ABAQUS. The deformation of pipes with the same section parameters and soil cover thickness but with different nominal diameters under various backfill conditions was studied. The numerical results were compared with the field tests. 


\section{Finite Element Model}

2.1. The Mesh of the 3D Pipe-Soil Model. Since the shape of the outer wall of the HDPE pipe is corrugated, the shape of the soil in contact with the pipe is also corrugated, which makes it difficult to divide the soil. The finite element preprocessing software HYPEIMESH can be used to divide the soil mesh. Fang et al. increased the size of soil elements by reducing element nodes. Similar methods are used to deal with soil mesh in the paper [32,33]. By dividing the soil grid skillfully, the number of soil elements is reduced from 1.5 million to 220,000 per meter, and the calculation efficiency of the accurate $3 \mathrm{D}$ model of corrugated pipe soil is greatly improved. The element accuracy of the contact area between the soil and the pipe has the most obvious influence on the calculation results. Therefore, when analyzing the grid sensitivity of the model, the crest strain distribution of the model with different minimum element sizes can be compared as evidence to judge the optimal element size of the model.

To study the influence of model grid size change on the simulation results, the minimum size of the grid of the pipesoil model with a diameter of $600 \mathrm{~mm}$ is set as $1 \mathrm{~mm}, 3 \mathrm{~mm}$, $5 \mathrm{~mm}$, and $10 \mathrm{~mm}$, respectively. The simulation results of four models with different element minimum sizes are shown in Figure 1. It can be found that when the minimum size of the element is $3 \mathrm{~mm}$ and $5 \mathrm{~mm}$, the peak strain value is very close, slightly smaller than the crest strain value when the minimum size is $1 \mathrm{~mm}$. However, when the minimum size of the element is $10 \mathrm{~mm}$, the strain distribution law of the wave crest changes obviously, which means that the accuracy of the element is poor, and it cannot simulate the deformation of the pipe under actual conditions. In general, the accuracy of the calculation increases as the number of elements increases. To improve the calculation efficiency, the number of elements should be reduced as much as possible while ensuring the accuracy of the calculation. In this paper, the minimum element size is $5 \mathrm{~mm}$, ensuring calculation accuracy and efficiency.

2.2. The 3D Model of Pipes. To facilitate the calculation, the numerical model is simplified. Based on the characteristics of the corrugated pipe, the following assumptions are made: (1) The pipe and soil are both isotropic materials and (2) the thickness of the interior and exterior walls of the pipe is constant.

Although HDPE is a viscoplastic material, the deformation of the HDPE pipe subjected to external loads is linear in the short term. The initial deformation would occur after completing the pipe installation, and the pipe depends on its short-term mechanical properties to resist the external loads. Therefore, this deformation can be simplified as elastic deformation [34].

The compressive stress-strain curve of HDPE shows that there is no significant turning point in the elastic and plastic stages of the material, and it shows pronounced nonlinearity in the later stage of the elastic stage. By analyzing the micro and macro behaviors of amorphous polymers, Jin (2016)

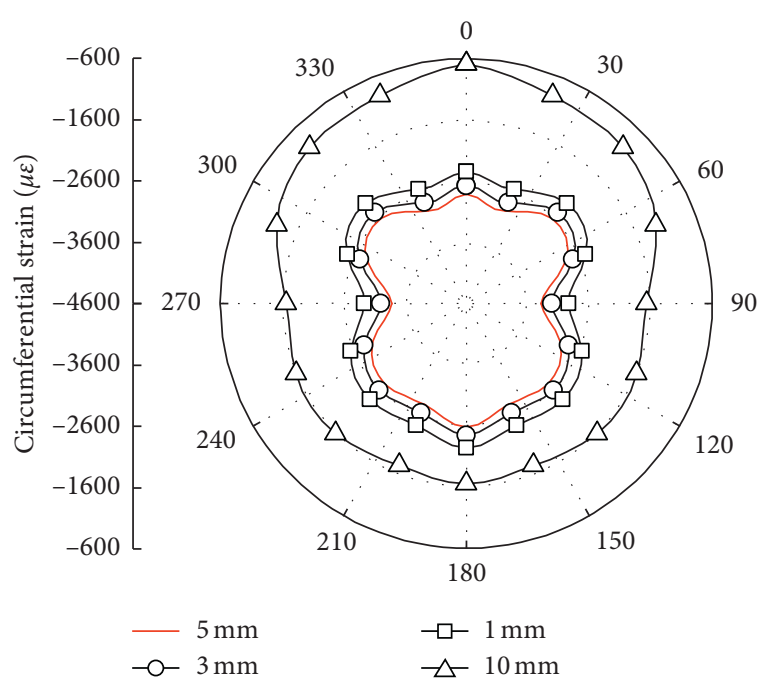

FIgURE 1: The circumferential strain of crest with different minimum element sizes.

found that although the polymer material showed particular nonlinearity in the elastic stage, the linear elastic model could also be used to approximately describe the elastic stage of the material [35]. Xu et al. (2019) studied the compressive mechanical properties of polyethylene materials at different strain rates through material tests [36]. In the elastic stage, the linear elastic model considering strain rate was adopted, and the bilinear curves of elastic modulus and strain rate in different strain rate ranges are fitted. It is found that the linear elastic model can well fit the stress-strain curve of high-density polyethylene under quasi-static (strain rate is $10^{-3}$ ) conditions. The strain rate considered in this paper is far less than $10^{-3}$, and the actual deformation of the pipeline is far less than the elastic limit strain value. At this time, the elastic deformation of HDPE should be very close to the linear elastic deformation. Therefore, it is credible to simulate the mechanical behavior of the pipeline by linear elastic model (Figure 2).

The ratio of the pipe wall to the pipe diameter of the double-wall corrugated pipe is less than $1 / 20$, so the linear elastic materials and four-node reduced integral shell element (S4R) can be used to simulate the pipes in ABAQUS. According to the Technical specification for a buried plastic pipeline of sewer engineering (CJJ 143-2010), Table 1 shows HDPE pipes' parameters in the numerical simulation [37].

The corrugated section parameters of the pipe are shown in Table 2. The finite element model of the corrugated pipes with $800 \mathrm{~mm}$ nominal diameter is established according to the section parameters, as shown in Figure 3. The interaction between the pipe and the soil is simulated by the contact algorithm; "hard contact" is used to simulate the regular contact between pipe and soil, and the separation of pipe and soil is allowed.

The tangential friction coefficient between the pipe and the soil is determined by the smoothness of the pipe and the parameters of the soil particles. According to the literature, the pipe-soil friction coefficient of polyethylene pipes ranges from 0.3 to 0.4 (Zhu et al., 2006) [38]. The critical tangential force of is 


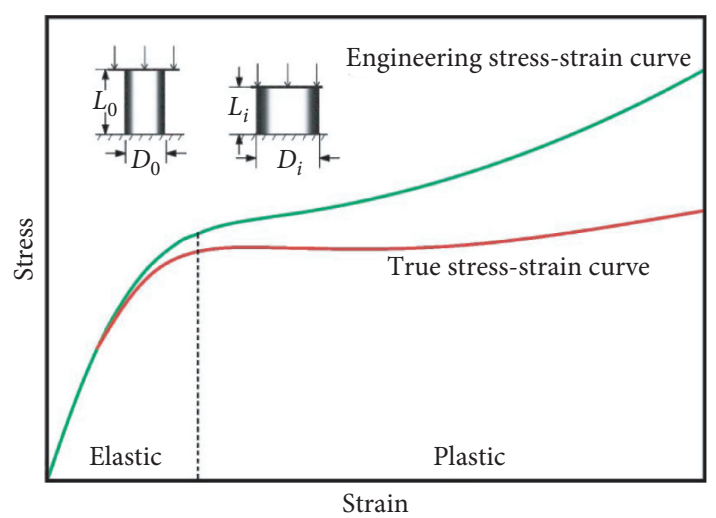

FIGURE 2: Polyethylene compressive stress-strain curve [34].

TABle 1: Mechanical parameters of the HDPE double-wall corrugated pipes in the numerical simulation.

\begin{tabular}{lc}
\hline Parameter & Value \\
\hline Elastic modulus $(\mathrm{MPa})$ & 800 \\
Density $\left(\mathrm{kg} / \mathrm{m}^{3}\right)$ & 950 \\
Poisson's ratio & 0.4 \\
\hline
\end{tabular}

TABLE 2: Corrugated section parameters of the HDPE double-wall corrugated pipes in the numerical simulation.

\begin{tabular}{lc}
\hline Parameter $(\mathrm{mm})$ & Value \\
\hline Corrugation length & 100 \\
Corrugation height & 45 \\
Thickness of the exterior wall & 2 \\
Thickness of the interior wall & 2 \\
\hline
\end{tabular}

$$
\tau_{\text {crit }}=\mu * P,
$$

where $\tau_{\text {crit }}$ is the critical tangential force, $\mu$ is the tangential friction coefficient, $P$ is the contact pressure in the normal direction of the pipe.

If the tangential force of the pipe is less than the critical tangential force, the friction surface would not slide relative to each other. To discuss the influence of the friction coefficient on the simulation results, we set the friction coefficient to $0.25,0.3,0.35,0.4$. Figure 4 shows the distribution of crest circumferential strain under different friction coefficients. In the numerical simulation of the paper, the influence of the friction coefficient on the strain distribution law of the pipe is negligible. Considering that the backfill is medium-fine sand, the smaller value of friction coefficient $(0.3)$ is taken in this paper. By comparing the field data with the simulation values, it is proved that the value of the friction coefficient is feasible.

2.3. The 3D Model of the Soil. To reduce the number of soil elements and simplify the analysis, the finite element model does not simulate the road structure, and only a foundation model comprising backfill and in-situ soil is included. The soil model is $4 \mathrm{~m}$ long, $5 \mathrm{~m}$ wide, and $4.2 \mathrm{~m}$ high. The size of the soil and the layering of the backfill in the numerical simulation are shown in Figure 5.

In this paper, the influence of backfill compaction on pipe deformation during installation is not considered but more attention is to be paid to the pipe deformation after the pipe-soil interaction is stable. The constitutive model of soil in this paper is Mohr-Coulomb [39]. The soil element adopts an eight-node reduced integral solid element (C3D8R) with hourglass control [40-42]. Element sets with specific material parameters are established to represent different soil areas. The soil parameters used for the numerical simulation are shown in Table 3.

The backfill around the pipe is layered for the requirements of the pipe construction specification and simulated for the different compaction of backfill by changing the elastic modulus of soil. The layer thickness and the corresponding elastic modulus of the soil are shown in Figure 6. The flexible pipe and soil deform together to resist the external load. The stiffness of soil and pipe determines the soil arch effect formed above the pipe, so the stiffness of the soil directly affects the stress deformation of the pipe. In the assembly process, backfill stiffness is mainly affected by the degree of compaction. The changes in the compaction degree of the backfill would influence the elastic modulus, Poisson's ratio, and cohesion of the soil, among which the elastic modulus change has the most significant effect on the pipesoil interaction. To simplify the analysis, this paper assumes that the looseness of the backfill only leads to a decrease in the elastic modulus of soil. At the same time, Poisson's ratio and cohesion remain unchanged. When the influence of the local looseness of the backfill on the pipe deformation is discussed, the elastic modulus of the soil is reduced to simulate the reduction of soil compaction.

According to the relationship between the compaction degree and elastic modulus of the soil given in the structural design code of pipes of water supply and wastewater engineering (GB 50332-2002) [43], the elastic modulus of loose backfill is set as $3 \mathrm{MPa}$ in the numerical simulation. The boundary conditions of the pipe-soil interaction model are as follows: the bottom of the soil is completely fixed, and the six degrees of freedom of the bottom nodes are set to 0 . The top surface of the soil is a free surface without any constraints. The other four lateral planes of pipe are perpendicular to the bottom plane, and only the degrees of freedom in the normal direction are limited. Based on the principle of static equivalency, the road structure is converted into a $50 \mathrm{kPa}$ uniform load applied directly above the soil to simulate its influence on the pipeline.

\section{Field Tests}

3.1. Test Materials and Equipment. For reliability in determining the strain distribution of a pipe interior wall, a largediameter HDPE double-wall corrugated pipe is used for field tests. The test pipe is $12.0 \mathrm{~m}$ long and has a nominal diameter of $800 \mathrm{~mm}$. To verify the accuracy of the pipe loose backfill conditions in the finite element model, the backfill soil from the invert to the left springline of the pipe is not compacted 


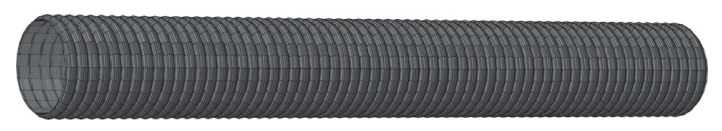

(a)

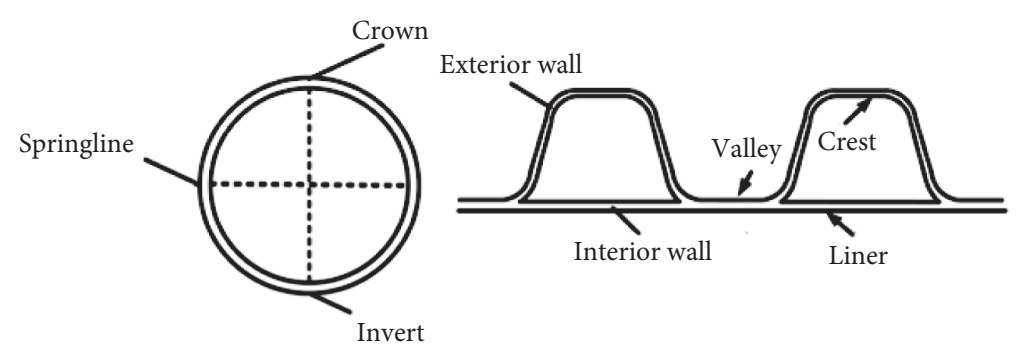

(b)

Figure 3: (a) The 3D model of the HDPE double-wall corrugated pipe. (b) Schematic diagram of the cross section of the double-wall corrugated.

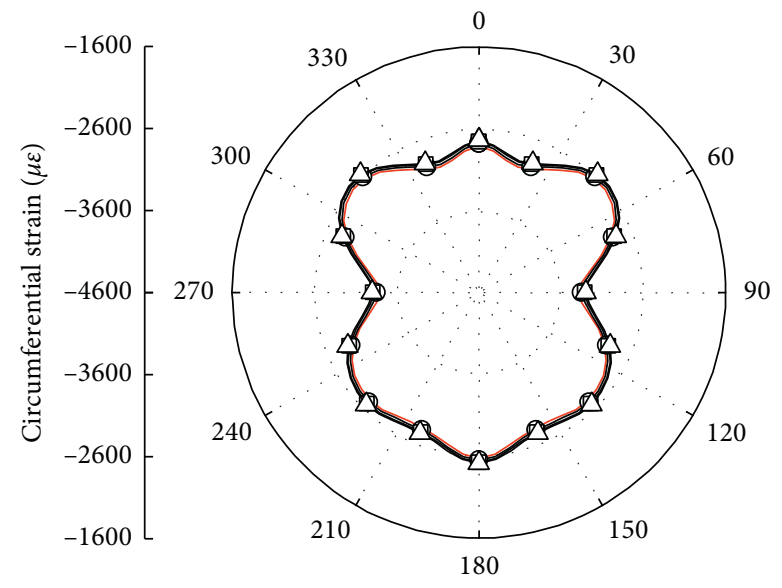

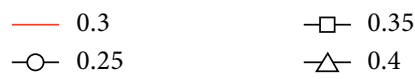

Figure 4: The circumferential strain of crest with the different friction coefficients.

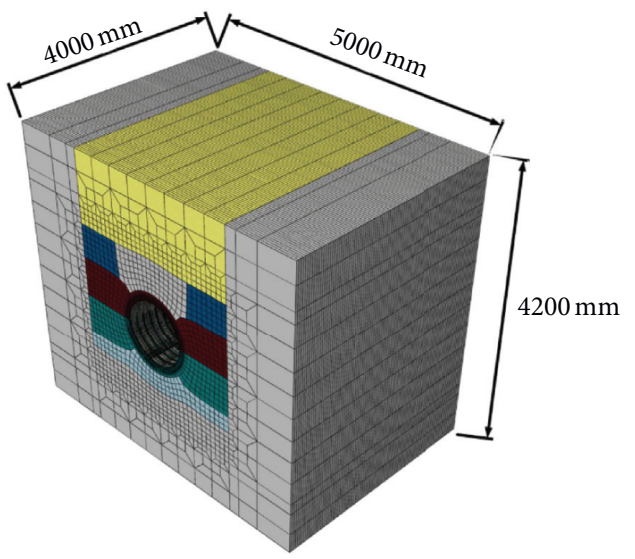

(a)

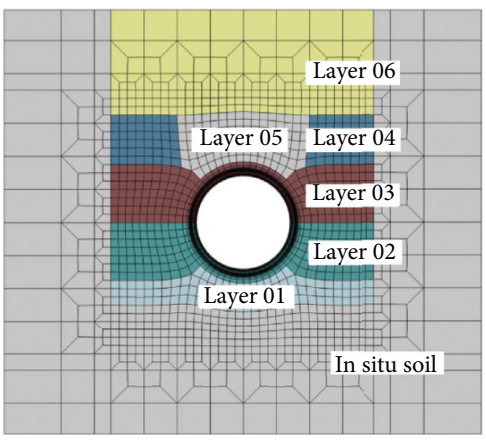

(b)

Figure 5: The 3D model of the soil.

in the field test. The rest of the area is compacted and backfilled according to the specifications and requirements.

To reduce the influence of boundary conditions on the measurement results, the section for collecting the pipeline strain is located in the middle of the pipeline, and a strain gauge (BQ120-80AA-P200) with an accuracy of $2.2 \mu \varepsilon$ is arranged on the measuring section to determine its circumferential strain. Eight strain gauge is arranged at the 
TABLE 3: Mechanical parameters of each layer of the backfill in the numerical simulation.

\begin{tabular}{|c|c|c|c|c|c|c|}
\hline $\begin{array}{l}\text { Backfill } \\
\text { layer }\end{array}$ & $\begin{array}{l}\text { Dry density } \\
\left(\mathrm{kg} / \mathrm{m}^{3}\right)\end{array}$ & $\begin{array}{c}\text { Compaction degree } \\
(\%)\end{array}$ & $\begin{array}{l}\text { Elastic modulus } \\
(\mathrm{MPa})\end{array}$ & $\begin{array}{c}\text { Internal friction angle } \\
\left({ }^{\circ}\right)\end{array}$ & $\begin{array}{l}\text { Cohesion } \\
(\mathrm{kPa})\end{array}$ & $\begin{array}{l}\text { Poisson's } \\
\text { ratio }\end{array}$ \\
\hline$L 01$ & 1800 & 90 & 5 & 35 & 12 & 0.25 \\
\hline L02 & 1750 & 95 & 7 & 26 & 10 & 0.25 \\
\hline$L 03$ & 1740 & 95 & 7 & 26 & 10 & 0.30 \\
\hline L04 & 1600 & 85 & 3 & 25 & 15 & 0.30 \\
\hline$L 05$ & 1600 & 90 & 5 & 35 & 15 & 0.30 \\
\hline L06 & 1650 & 90 & 5 & 30 & 12 & 0.30 \\
\hline In-situ soil & 1500 & - & 30 & 28 & 20 & 0.30 \\
\hline
\end{tabular}

\begin{tabular}{|c|c|c|c|}
\hline \multicolumn{4}{|c|}{ Ground } \\
\hline $\begin{array}{l}\text { In situ soil layered } \\
\text { backfill }\end{array}$ & & $\begin{array}{c}L 06 \\
5 \mathrm{MPa}\end{array}$ & $\begin{array}{l}\text { Upside of pipe } \\
1000 \mathrm{~mm}\end{array}$ \\
\hline $\begin{array}{l}\text { Medium-coarse sand or the } \\
\text { gravel of maximum grain }\end{array}$ & $\begin{array}{c}L 05 \\
5 \mathrm{MPa}\end{array}$ & $\begin{array}{c:c}L 04 & L 05 \\
3 \mathrm{MPa} & 5 \mathrm{MPa} \\
\end{array}$ & $\begin{array}{l}\text { Upside of pipe } \\
500 \mathrm{~mm}\end{array}$ \\
\hline Medium-coarse sand & L03 & $7 \mathrm{MPa}$ & $\begin{array}{l}\text { Bilateral } \\
400 \mathrm{~mm}\end{array}$ \\
\hline Medium-coarse sand & L02 & 7 & $\begin{array}{l}\text { Haunch } \\
400 \mathrm{~mm}\end{array}$ \\
\hline Medium-coarse sand & $L 01$ & $5 \mathrm{MPa}$ & Foundation $200 \mathrm{~mm}$ \\
\hline
\end{tabular}

In situ soil

FIgURE 6: Schematic diagram of thickness and elastic modulus of the backfill.

crest, valley, and liners of the pipeline, with an interval of $45^{\circ}$ between each strain gauge. The strain gauge is connected to the strain data acquisition instrument, and the strain reading is reset to zero before the pipeline is installed. The strain acquisition system uses the DH5921 dynamic stress strain test and analysis system produced by Jiangsu Donghua Testing Technology Co., Ltd., which amplifies and analyzes the electrical signals collected from the strain gauges and then transmits them to the computer. To ensure the accuracy of the data, the reading is recorded twice per second. After the load is applied to the ground for 5 minutes, the strain of each pipe section is monitored and recorded. Figure 7 shows the positions of vehicle load and strain gauge in the field test.

3.2. Assembly of the Test Pipe. The HDPE pipe is buried in a trench 12 meters long, 2.5 meters wide, and 2.4 meters deep, and the backfill is compacted with a vibratory plate compactor. Inspection wells constrain the two ends of the pipe. Medium-coarse sand is used for backfill. The specific parameters of the backfill are shown in Table 4, and the backfill compaction degree around the pipe is shown in Figure 8. The pipe installation process is as follows:

(1) The undisturbed trench bottom is covered with $200 \mathrm{~mm}$ of backfill (Layer 01) and compacted to $90 \%$.

(2) To prevent the pipe movement, both sides of the pipe must be backfilled symmetrically. The backfill from the invert to the springline of the pipe is defined as Layer 02 backfill. Layer 02 backfill on one side of the pipe remains loose and uncompacted. The remaining Layer 02 area is backfilled in layers with a thickness of $100 \mathrm{~mm}$ per layer and compacted to $95 \%$ of the specification.

(3) The backfill from the springline to the crown of the pipe (Layer 03 backfill) is backfilled in layers with a thickness of $100 \mathrm{~mm}$ and compacted to $95 \%$.

(4) The backfill in the area from the top to $0.5 \mathrm{~m}$ above the crown of the pipe is divided into two parts (Layer 04 and Layer 05 backfills). The backfill directly above the pipe (Layer 04 ) is compacted to $85 \%$, while the backfill on the two sides (Layer 05) is compacted to $90 \%$.

(5) From $500 \mathrm{~mm}$ above the pipe crown to $1000 \mathrm{~mm}$ thick on the ground (Layer 06 backfill), it is backfilled in layers with a thickness of $200 \mathrm{~mm}$ and compacted to $90 \%$.

\section{Analysis Results of Numerical Simulations}

4.1. Verification of the Numerical Model. To verify the accuracy of the finite element model, the on-site measured values and computed values are compared, as shown in Figure 9. It can be found that although the measured values and computed values significantly differ numerically, the strain distribution curves are very similar within the allowable range of error. To ensure the quality of the mesh, the soil is not cut into layers during the mesh division. The backfill layering is realized by assigning material parameters 

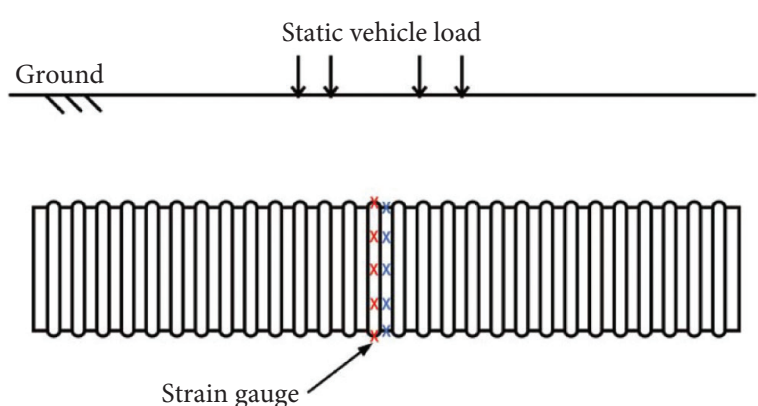

Figure 7: Diagram of vehicle load and strain gauge position.
TABle 4: Parameters of the backfill used in the field test.

\begin{tabular}{lc}
\hline Parameter & Value \\
\hline In situ soil & \\
Maximum dry density $\left(\mathrm{kg} / \mathrm{m}^{3}\right)$ & 1549 \\
Water content $(\%)$ & 12 \\
Liquid limit $(\%)$ & 25.9 \\
Plastic limit $(\%)$ & 17.3 \\
Porosity & 42.3 \\
\hline Backfill & \\
Maximum dry density $\left(\mathrm{kg} / \mathrm{m}^{3}\right)$ & 1730 \\
Coarse sand content $(0.5 \mathrm{~mm}-3 \mathrm{~mm})(\%)$ & 35 \\
Medium-coarse sand content $(0.35 \mathrm{~mm}-0.5 \mathrm{~mm})(\%)$ & 57 \\
Fine sand content $(0.25 \mathrm{~mm}-0.35 \mathrm{~mm})(\%)$ & 8 \\
Uniformity coefficient $\left(C_{u}\right)$ & 6 \\
Curvature coefficient $\left(C_{c}\right)$ & 1.5 \\
\hline
\end{tabular}

to the element set, so the backfill layer is curved. By comparing the full-scale field test, it is found that the test result is reliable, and the curving of the backfill area has little effect on the calculation result. The $3 \mathrm{D}$ finite element analysis can provide reliable results to study the mechanical response of the pipe under nonuniform backfill conditions, and the assumed elastic modulus for the loose backfill is credible.

\subsection{Deformation of Pipes with Different Nominal Diameters.} To discuss the influence of the nominal diameter on the mechanical response of the pipes, the pipe-soil models with the same thickness of soil cover and the same corrugated section parameters but with different pipe nominal diameters $(400 \mathrm{~mm}, 600 \mathrm{~mm}$, and $800 \mathrm{~mm})$ are prepared. The deformation characteristics of the pipe with different nominal diameters under various backfill conditions are determined from the finite element analyses, and their deformation distribution along the circumference is examined. For double-wall corrugated buried pipes, typically, the circumferential strain value for the pipe is much larger than the axial strain value. Therefore, in this paper, circumferential strain and radial displacement are taken as parameters to judge the deformation of the pipe, and the pipe strain mentioned hereafter refers to the pipe circumferential strain only.
4.2.1. Deformation of Pipes with Different Nominal Diameters under the Compaction Backfill Condition. Under the compaction backfill condition, the circumferential strain distribution diagrams of the interior and exterior walls of the pipe are compared. It is found that the smaller the interior diameter, the smaller the strain in both the walls; and the liner strain of the $400 \mathrm{~mm}$ pipe reverses from compressive strain $(600 \mathrm{~mm}$ and $800 \mathrm{~mm}$ pipes) to tensile strain (400 mm) over a small area (Figure 10). The circumferential strains at critical positions of the pipes with different diameters are extracted and plotted in Figure 11.

Figure 11 shows that the strain distribution curves corresponding to the valley and crest of the pipe with different nominal diameters are very similar; however, as seen from Figure 7(a), the nominal diameter has a more pronounced effect on the liner. The liner strains of the $600 \mathrm{~mm}$ and $800 \mathrm{~mm}$ pipes are compressive strains consistently with analogous variation along the circumference, which is very akin to the strain variation in the valley and crest. The strain in the $600 \mathrm{~mm}$ pipe is lower than that for the $800 \mathrm{~mm}$ pipe. For the $400 \mathrm{~mm}$ pipe, however, the liner strain becomes positive. However, the distribution is consistent with the circumferential strain distribution of the 600 or $800 \mathrm{~mm}$ pipe, except that in the case of $400 \mathrm{~mm}$ pipe, positive strain is increasing, while in larger-diameter pipes, the negative strain is increasing; hence, for all pipes, the strain increases numerically from the crown to the springline of the pipe, and it decreases from the springline to the invert of the pipe, and the numerically maximum strain appears at the springline of the pipeline.

The positive strain in the pipe with a small diameter can be explained by studying the deformation of corrugated sections. In the present case, magnifying the deformation of the $400 \mathrm{~mm}$ pipe 20 times, the distorted shape of the interior wall is observed to be "corrugated", which is consistent with the section deformation diagram of the corrugated pipes given by Dhar (2002) [44] (Figure 12). At the location where the interior and exterior walls of the pipe are in contact, the interior wall and exterior wall are jointly displaced by the soil against the pipe to have inward displacement, forming a shape similar to a "valley," while the liner is bent due to the inward displacement of the valley, forming a shape similar to a "crest." It can be considered that the radial displacement of 


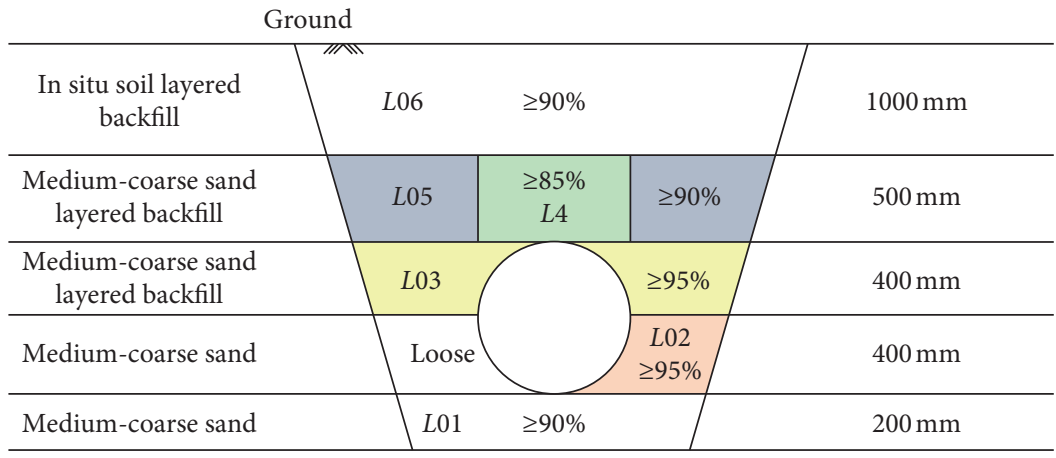

In situ soil

Figure 8: Schematic diagram of compaction of in situ backfill.

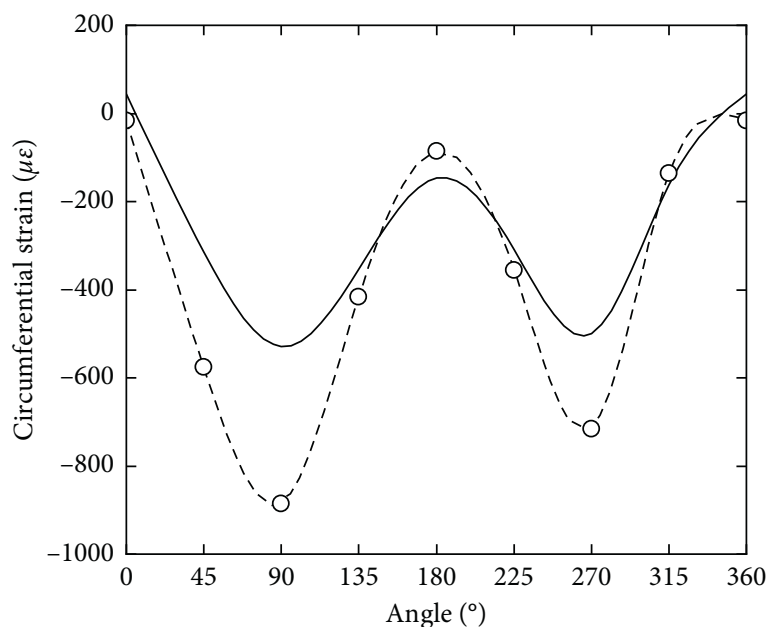

- Num-liner

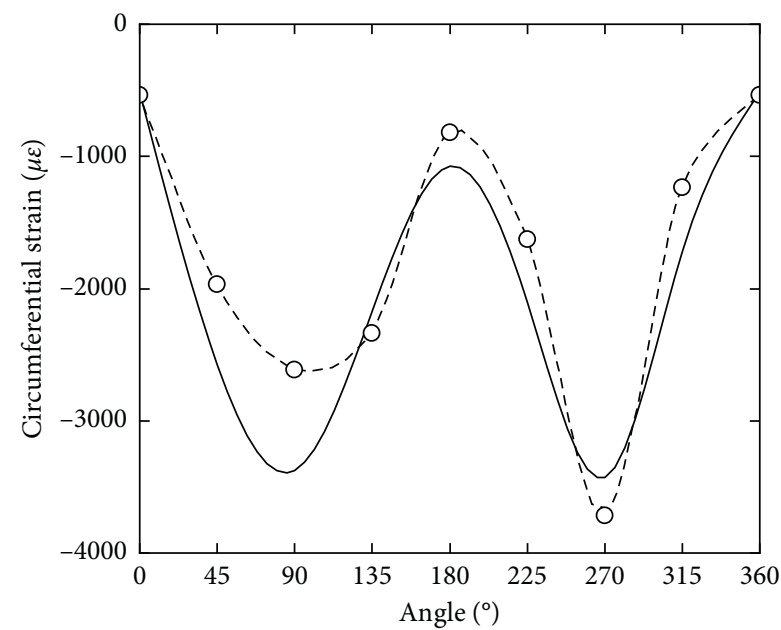

- Num-valley

(a)

(b)

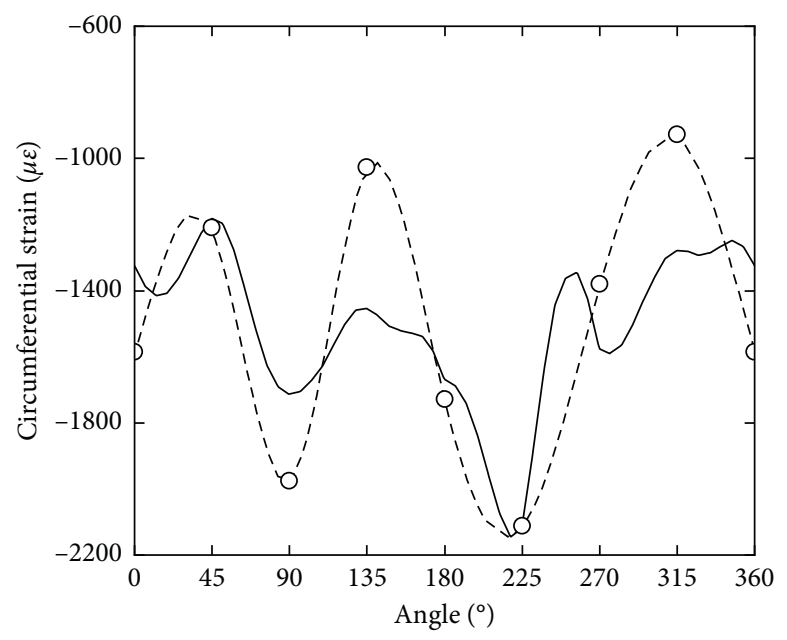

- Num-crest

-o- Test-crest

(c)

FIGURE 9: Comparison of measured and computed values of the strains when layer 02 backfill is locally loose. (a) Circumferential strain in the liner. (b) Circumferential strain in the valley. (c) Circumferential strain in the crest. 
LE, LE22 (Assembly_NB_ORI-1)

SNEG $($ fraction $=-1,0)$

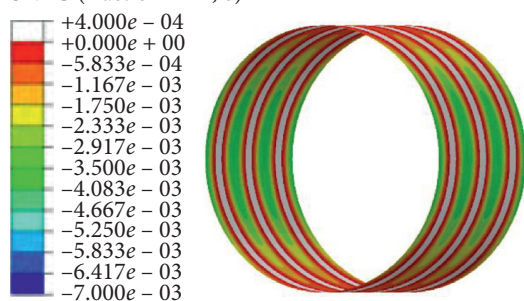

$400 \mathrm{~mm}$

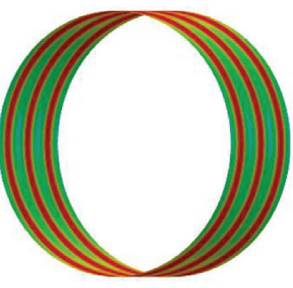

$600 \mathrm{~mm}$

(a)

LE, LE22 (Assembly_NB_ORI-1)

SNEG (fraction $=-1,0$ )

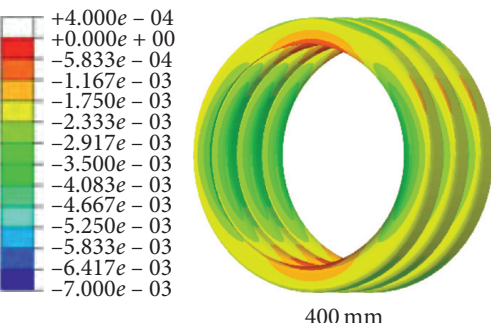

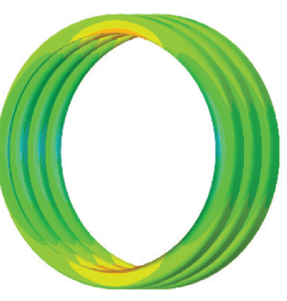

$600 \mathrm{~mm}$

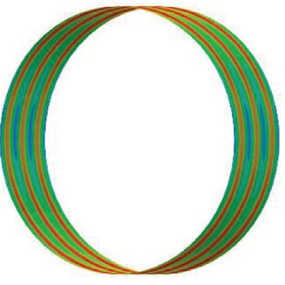

$800 \mathrm{~mm}$

(b)

Figure 10: Circumferential strain distribution diagrams for pipes with different diameters. (a) Interior wall of the pipe. (b) Exterior wall.

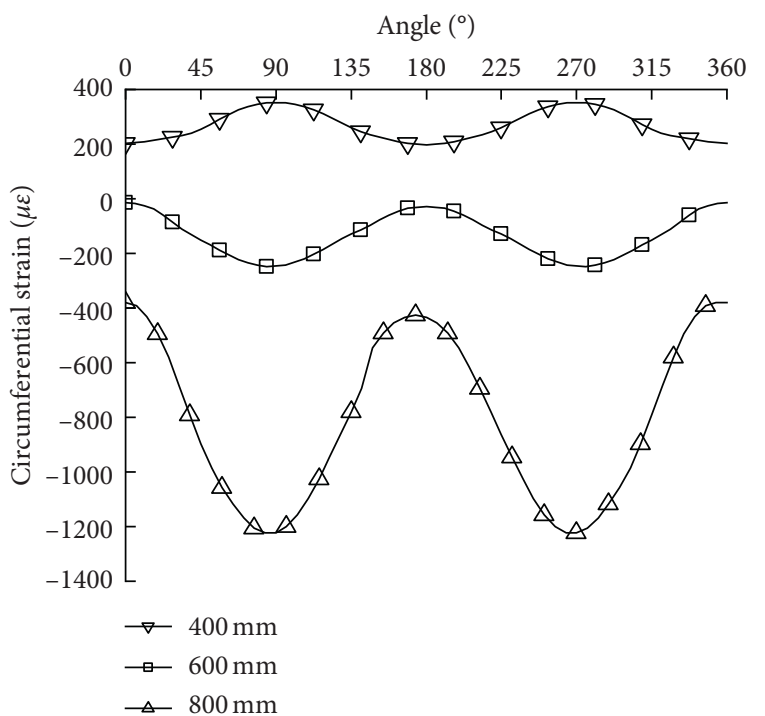

(a)

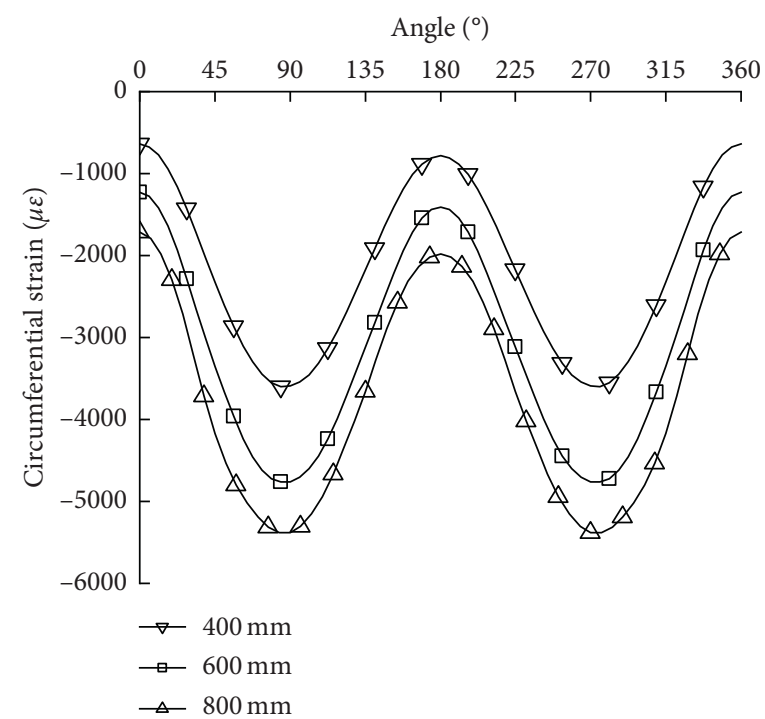

(b)

FIgURE 11: Continued. 


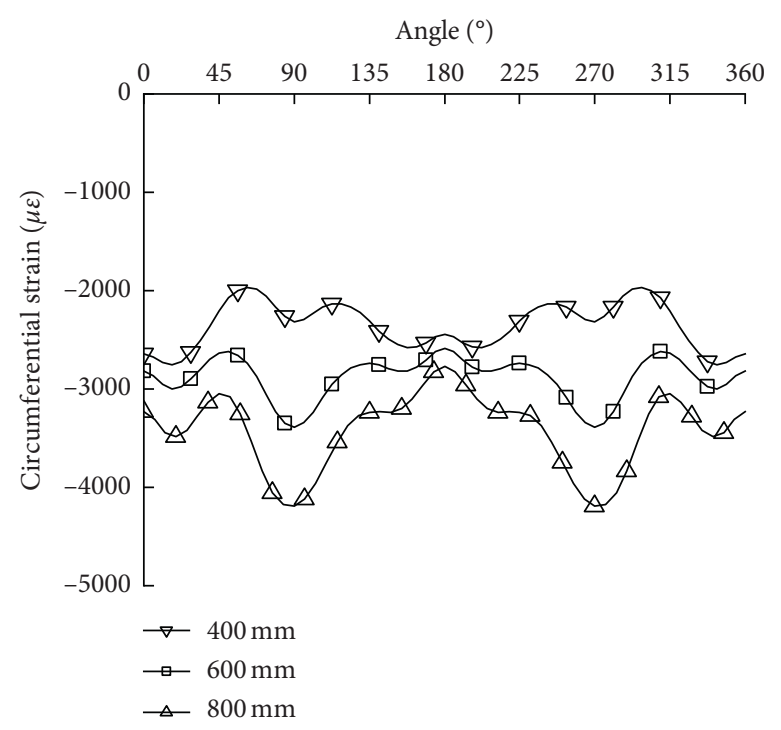

(c)

FIGURE 11: Circumferential strain distribution for the pipes with different diameters under the compaction backfill condition. (a) Liner. (b) Valley. (c) Crest.

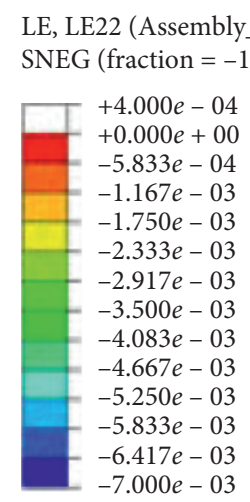

FIgURE 12: (a) A magnified view of the interior wall deformation of the $400 \mathrm{~mm}$ pipe. (b) A schematic diagram of the deformation of the corrugated section.

the valley determines the liner strain distribution. As shown in Figure 13(a), all the three pipes' radial displacements are almost indistinguishable throughout the circumference except perhaps at the crown. If the ratio of the radial displacement to the pipe diameter is set as $n$, it is found that along the circumference, the $n$ value of the $400 \mathrm{~mm}$ pipe is greater than that of the $600 \mathrm{~mm}$ and $800 \mathrm{~mm}$ pipes. That is, as shown in Figure 13(b), the inward "valley" deformation ratio of the interior wall of the $400 \mathrm{~mm}$ pipe is greater than the corresponding ratios for the pipes with greater diameters, which causes the circumferential strain at the "crest" of the interior wall to change from compression to tension.

4.2.2. Deformation of Pipes with Different Nominal Diameters under the Locally Loose Backfill Condition. The deformation states of pipes with different nominal diameters have been discussed above. It is found that the strain distribution form for $400 \mathrm{~mm}$ pipes and larger-diameter (600 $\mathrm{mm}$ and $800 \mathrm{~mm}$ ) pipes differ for the crest and liners under the compaction backfill condition. To further study the deformation of pipes with different diameters, the analysis is performed for the pipes with diameters of $400 \mathrm{~mm}, 600, \mathrm{~mm}$, and $800 \mathrm{~mm}$ buried in soil having the loose backfill in different areas, and assuming that the elastic modulus of the loose backfill material is $3 \mathrm{MPa}$.

The circumferential strain distributions for the pipes with different diameters under three types of locally loose backfill conditions are compared (Figures 14-16). It is found that the relationships between the strain and the nominal diameter of the pipe under poor and dense backfill conditions are consistent. When the backfill around the pipeline is 


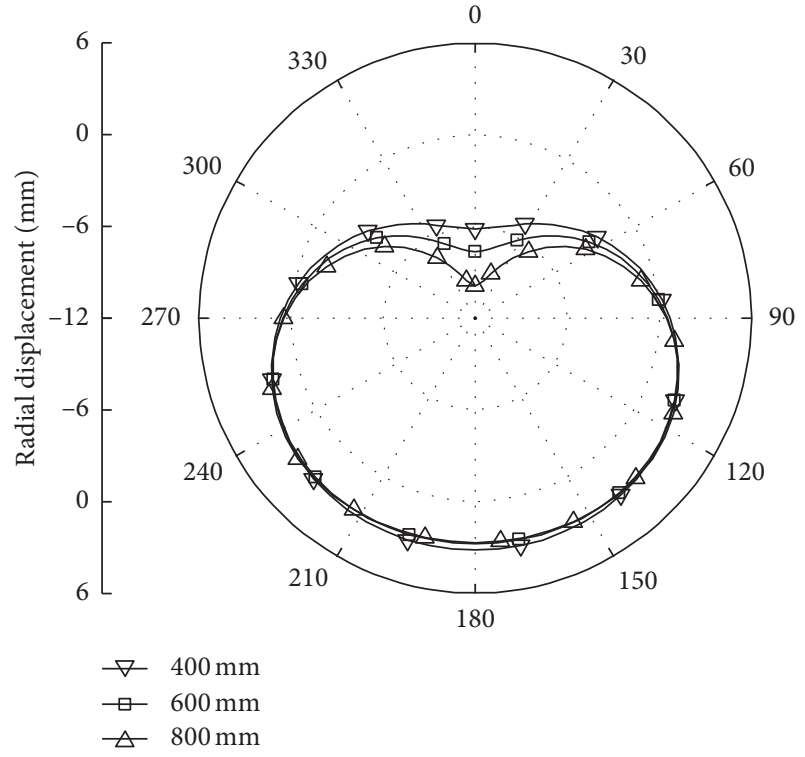

(a)

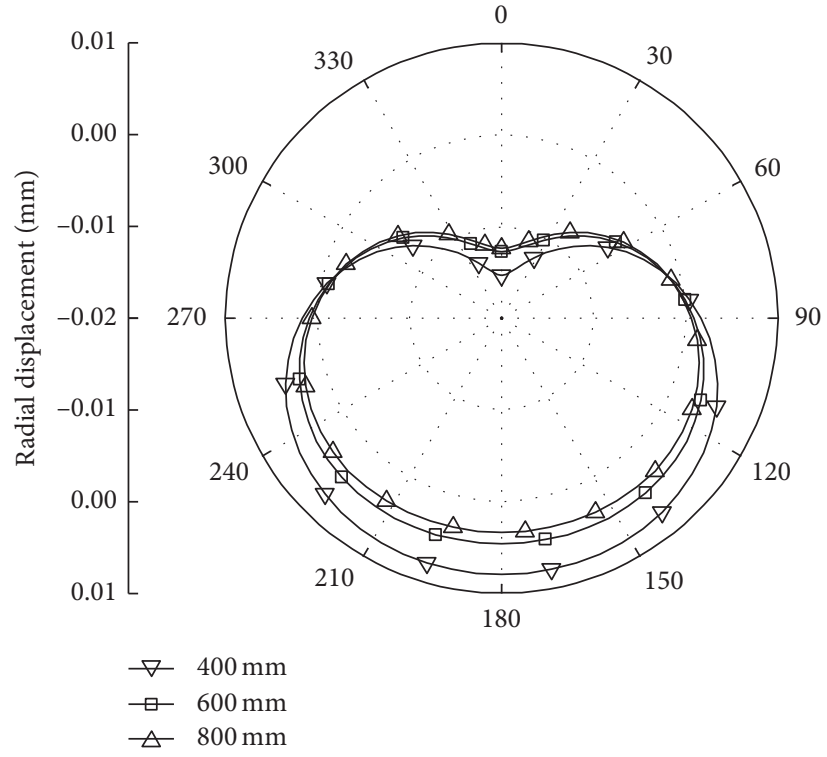

(b)

FIgURE 13: (a) Radial displacement distribution. (b) Ratio (radial displacement to nominal diameter) distribution when the soil around the pipe is densely backfilled.

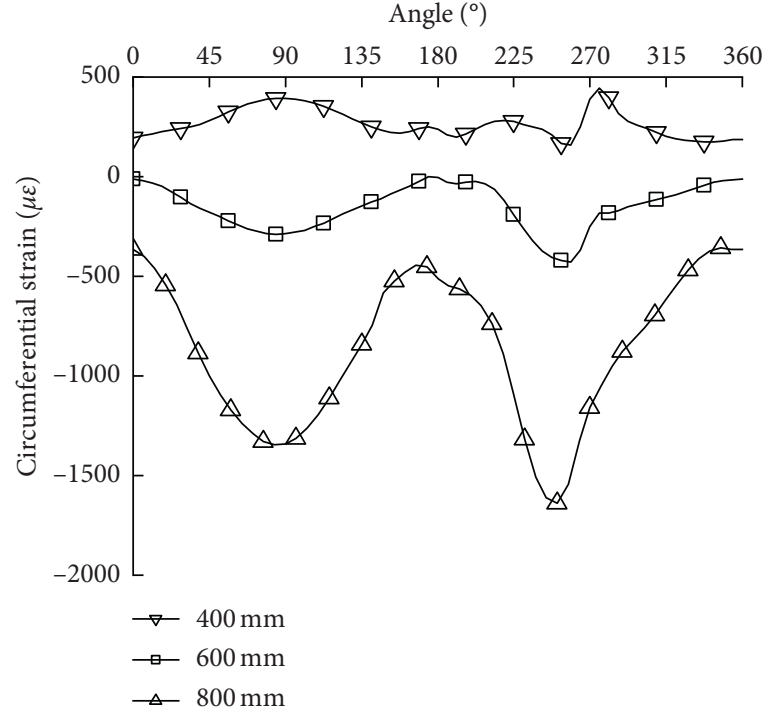

(a)

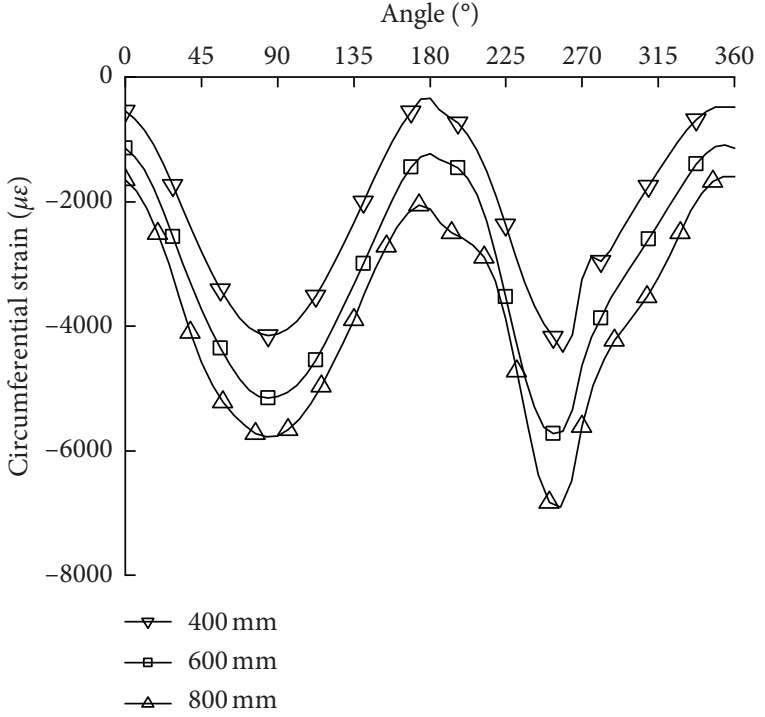

(b)

Figure 14: Continued. 


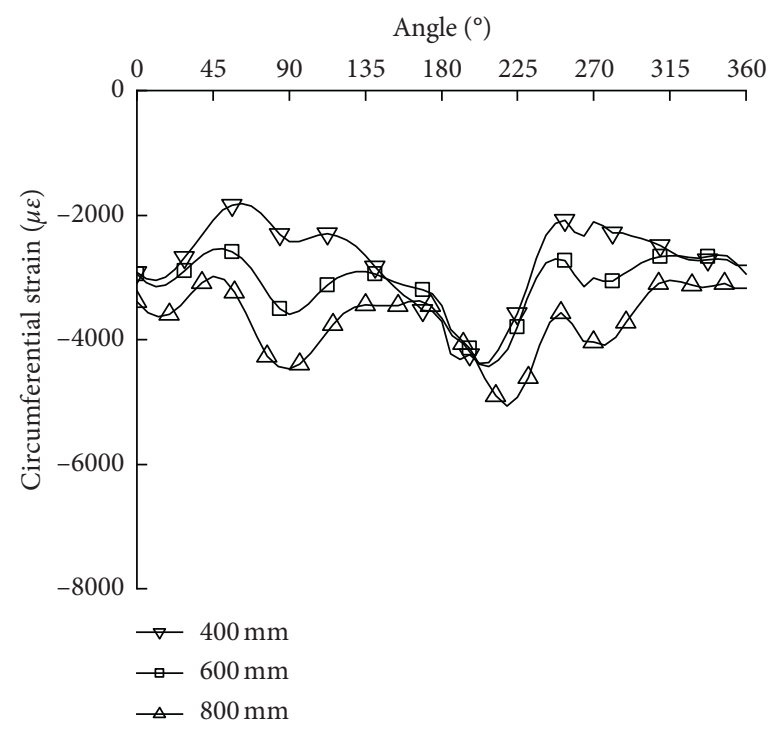

(c)

FIGURE 14: Circumferential strain distribution for the pipes with different diameters when the backfill on the left side of layer 02 is loose. (a) Liner. (b) Valley. (c) Crest.

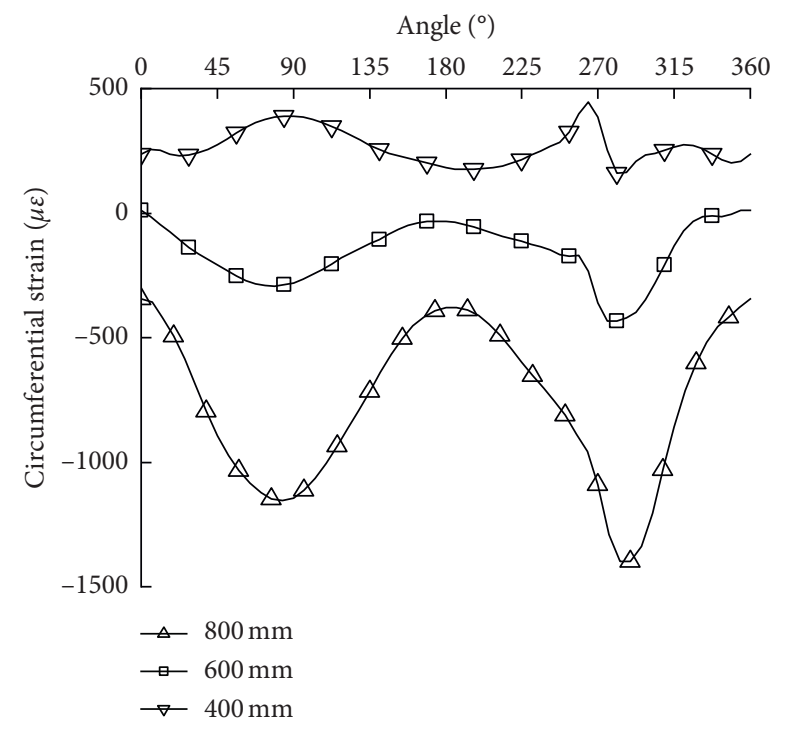

(a)

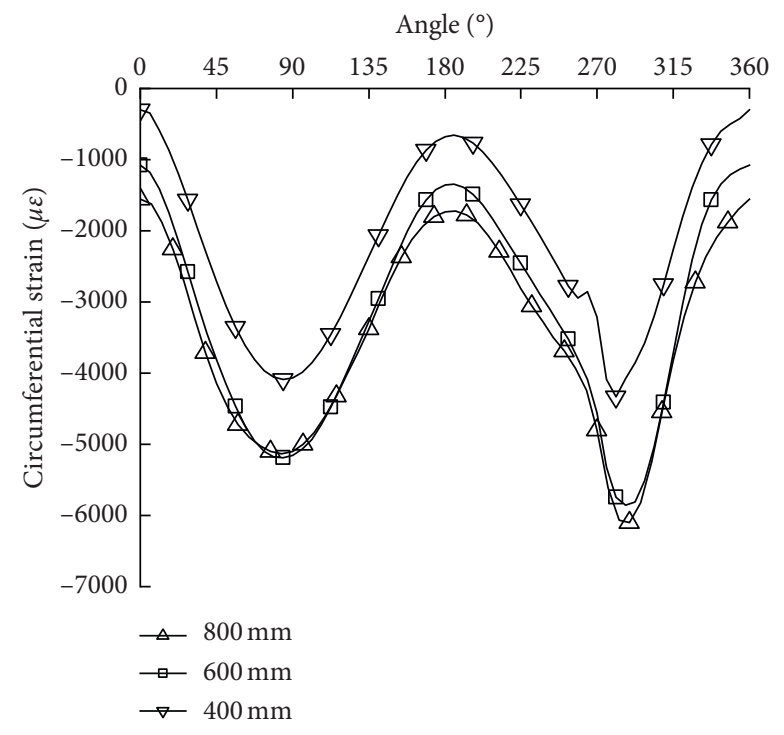

(b)

FIGURE 15: Continued. 


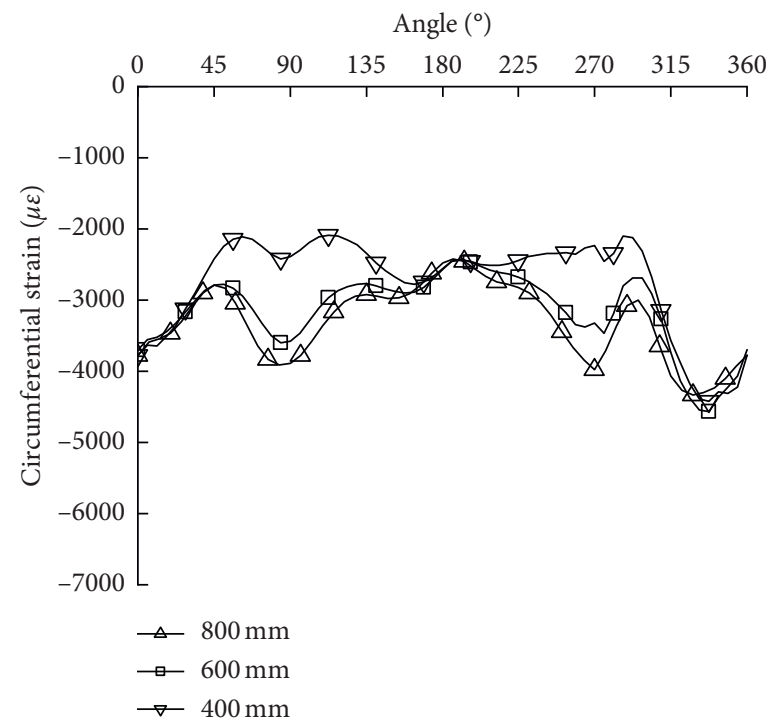

(c)

FIGURE 15: Circumferential strain distribution for the pipes with different diameters when the backfill on the left side of layer 03 is loose. (a) Liner. (b) Valley. (c) Crest.

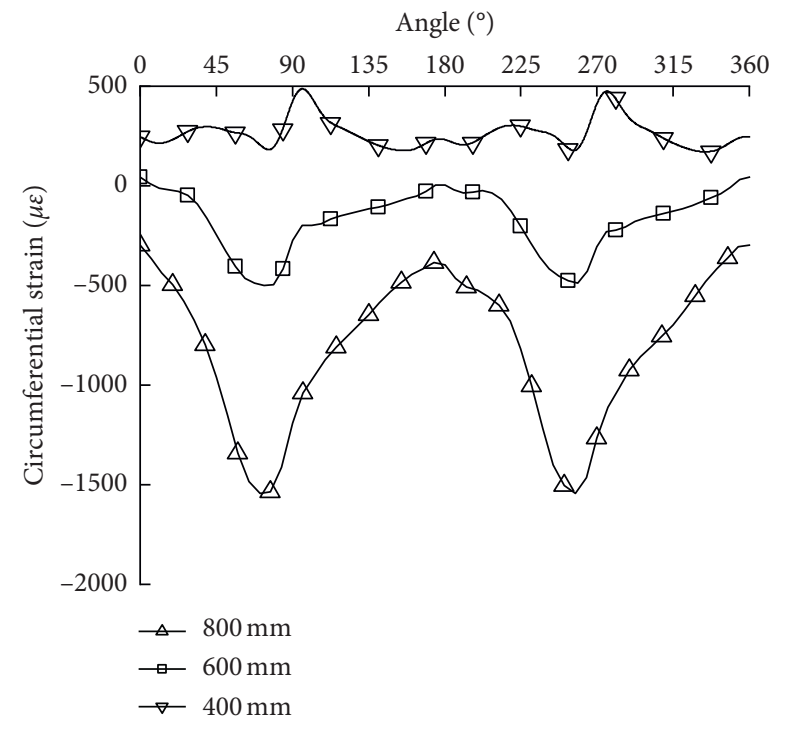

(a)

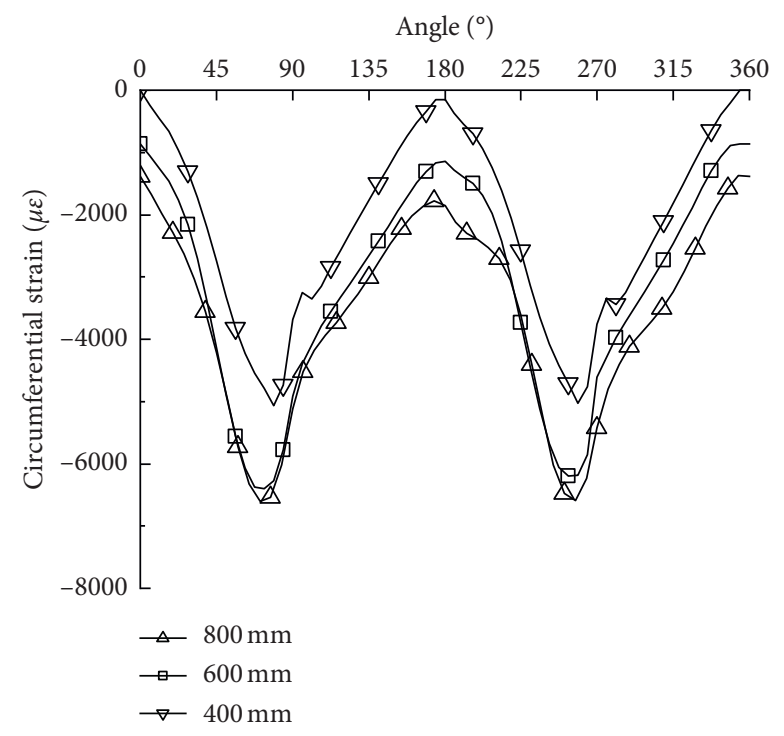

(b)

FIgURE 16: Continued. 


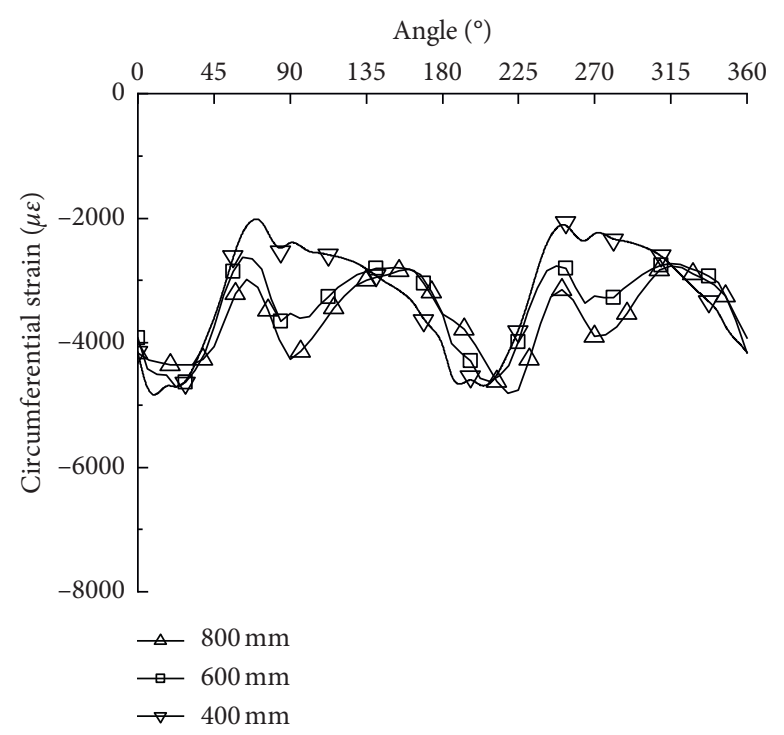

(c)

FiguRE 16: Circumferential strain distribution for the pipes with different diameters when the backfill on the left side of layer 02 and right side of layer 03 is loose. (a) Liner. (b) Valley. (c) Crest.

uniformly dense, the liner strain in the $400 \mathrm{~mm}$ pipe is tensile, and the circumferential strain in the liner of the $600 \mathrm{~mm}$ pipe is always compressive and less than that of the $800 \mathrm{~mm}$ pipe. At the crest and valley of the pipes, the circumferential strain is proportional to the nominal diameter; and in each case, the maximum strain occurs at relatively the exact locations. The strain distribution characteristics of $600 \mathrm{~mm}$ and $800 \mathrm{~mm}$ pipes are similar, while that of the $400 \mathrm{~mm}$ pipe are somewhat different. Therefore, the strain distributions of the $400 \mathrm{~mm}$ pipe under different loose backfill conditions are further analyzed to clarify the deformation characteristics of the pipes with small diameters buried in the poor backfill.

Figure 17 shows the distribution of circumferential strain and radial displacement of the $400 \mathrm{~mm}$ pipe under the loose backfill condition on the left side of Layer 02 . It can be seen that when the backfill near the haunch is loose, the strain distribution at crest and valley of the $400 \mathrm{~mm}$ pipe is asymmetric, which means that the pipe has undergone eccentric deformation. The crest strain at the lower part of the pipe increases significantly, reaching the maximum in the area near the pipe invert. The valley strain increases slightly at the springline and invert of the pipe, and it decreases from the left springline to the crown area of the pipe, reaching the maximum near the left springline in contact with the loose backfill. Compared with the strain distribution of the $800 \mathrm{~mm}$ pipe under the same backfill condition (Figure 10), it can be seen that the presence of loose backfill influences the crest and valley of the pipe in essentially the same manner. For the pipe liner, in the presence of loose Layer 02 backfill, the strain in the $400 \mathrm{~mm}$ pipe is almost the same as that under the compaction backfill. However, the literature shows that the $800 \mathrm{~mm}$ pipe liner strain increases near the interface between the loose backfill (Layer 02) and compaction backfill (Layer
03). It means that compared with large-diameter pipelines, the liner strain of small-diameter pipelines is less sensitive in response to the backfill compaction.

Under the same backfill condition, the effect of the loose backfill on pipes with different diameters is not the same. When the loose area is the left side of Layer 02, the crest strain of the $400 \mathrm{~mm}$ pipe increases significantly in the range of $90^{\circ}-225^{\circ}$, while the increase in the crest strain of the $800 \mathrm{~mm}$ pipe is over the range of $180^{\circ}-225^{\circ}$.

The radial displacement of the $400 \mathrm{~mm}$ pipe remains essentially unchanged in the contact area with the compaction backfill on the right side. On the left side, the radial displacement increases due to the weakening support of the backfill of the area (Figure 13(b)). Similar conclusions have been reported in the literature: when the backfill below the pipe hip is loose and there is well-compacted soil in the rest of the surrounding, the pipe deformation becomes an "inverted heart," the pipe strain is redistributed, and the strain concentration appears at the pipe hip. It is similar to the radial displacement of the $800 \mathrm{~mm}$ pipe when the backfill on the left side of Layer 02 is loose.

As shown in Figure 18, when the backfill on the left side of Layer 03 is loose, the impact on the $400 \mathrm{~mm}$ pipe is mainly reflected by the increase in the crest strain at the area of the pipe in contact with the loose backfill, and the maximum value of the crest strain occurs near the crown. Under this backfill condition, the valley strain increases slightly near the right springline of the pipe and decreases slightly from the invert to the left springline of the pipe. In the contact area of the backfill at the left springline of the pipe, the valley strain reaches its maximum, which means under poor backfill conditions, the valley strain has a significant difference over a small range, and the pipe undergoes significant eccentric deformation. With Layer 03 loose on the left side, the liner 


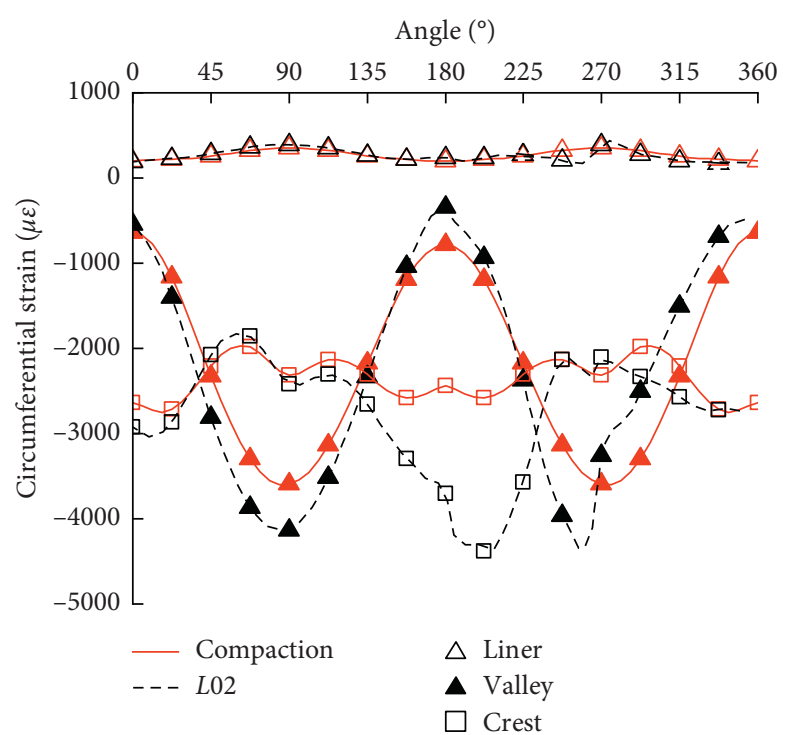

(a)

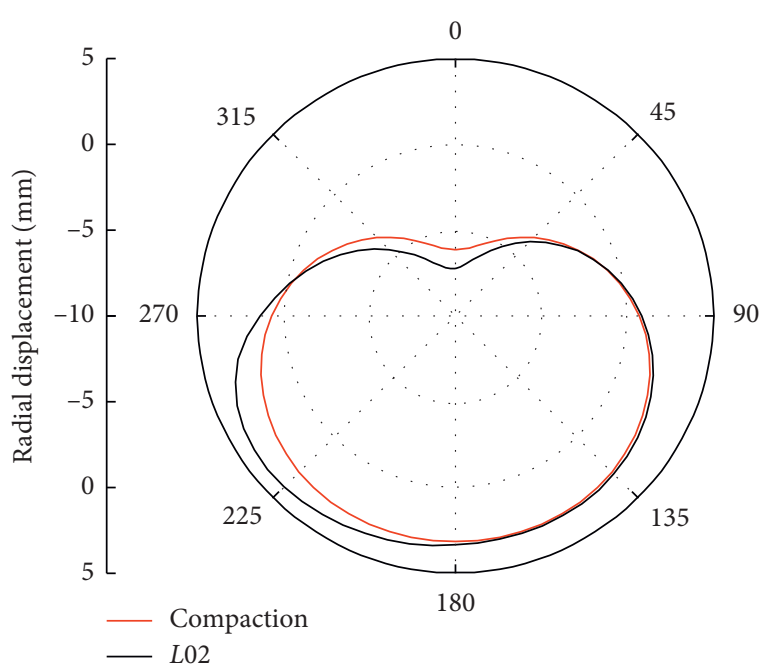

(b)

FIGURE 17: (a) Circumferential strain distribution. (b) Radial displacement distribution for the $400 \mathrm{~mm}$ pipe when the backfill on the left side of layer 02 is loose.

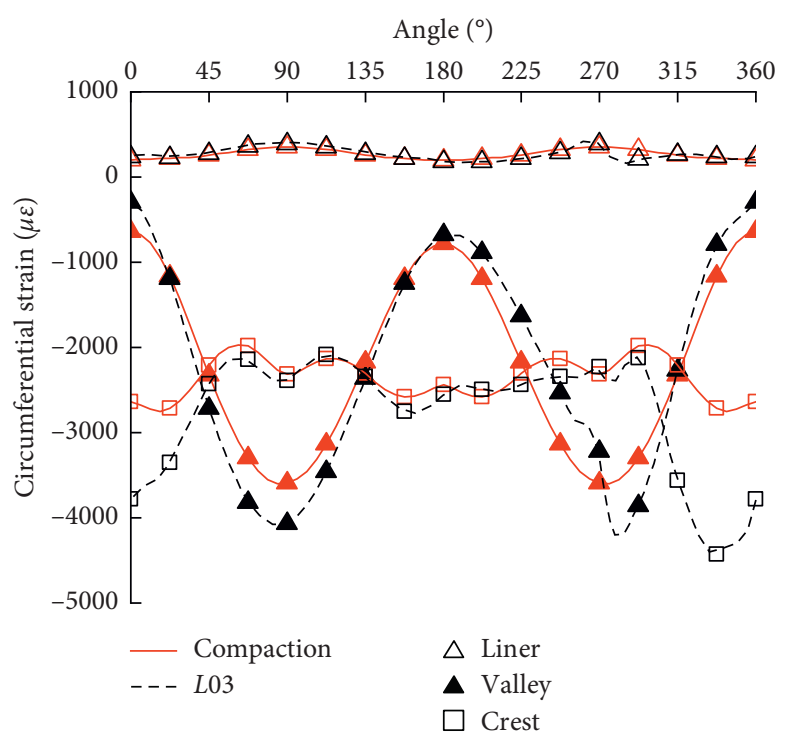

(a)

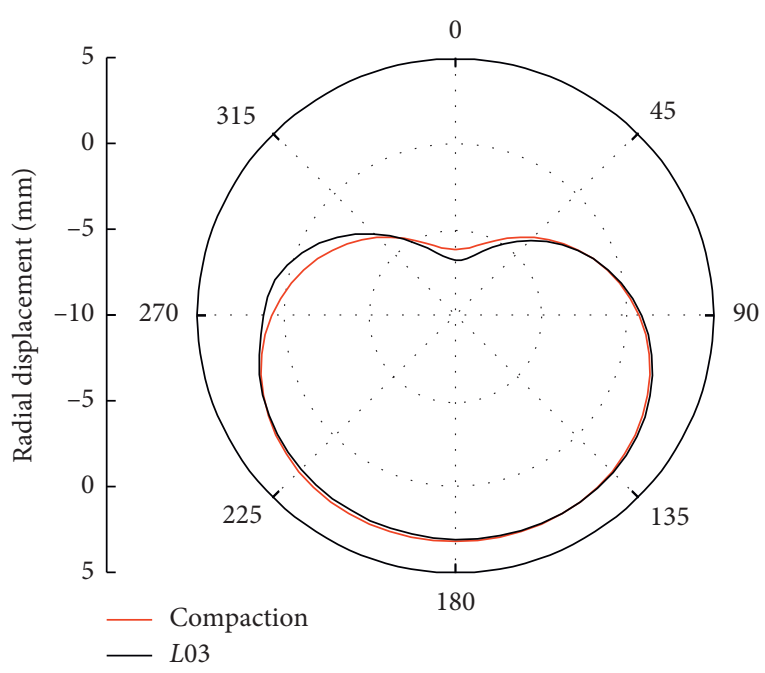

(b)

FIgURE 18: (a) Circumferential strain distribution. (b) Radial displacement distribution for the $400 \mathrm{~mm}$ pipe when the backfill on the left side of layer 03 is loose.

strain of the pipe hardly changes, which is similar to when the backfill on the left side of Layer 02 is loose. In comparison with the deformation of the $800 \mathrm{~mm}$ pipe under the same backfill condition, it is found that the area of influence by the loose backfill on the left side of Layer 03 and the strain distribution characteristics of pipelines with different diameters is somewhat similar. The loose backfill affects the valley strain of the $800 \mathrm{~mm}$ pipe more than its effect on the crest strain or liner strain, while for the $400 \mathrm{~mm}$ pipe, it is the crest that is affected more than the valley or the liner. In this case, the radial displacement of the pipe changes very little and only slightly increases on the left springline and the crown areas of the pipe.

Figure 19 plots the circumferential strain and displacement at each point of the $400 \mathrm{~mm}$ pipe under the condition that the backfill on the left side of Layer 02 and the right side of Layer 03 is loose. As shown in the figure, the valley strain in the contact area with the compaction backfill decreases, while that in the contact area with the loose backfill increases. There are two maximum values of the 


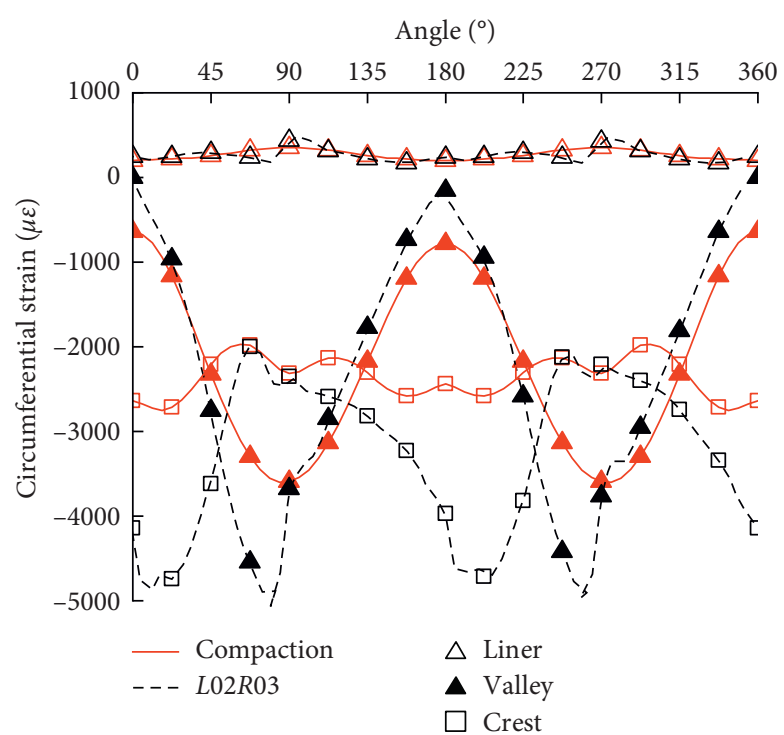

(a)

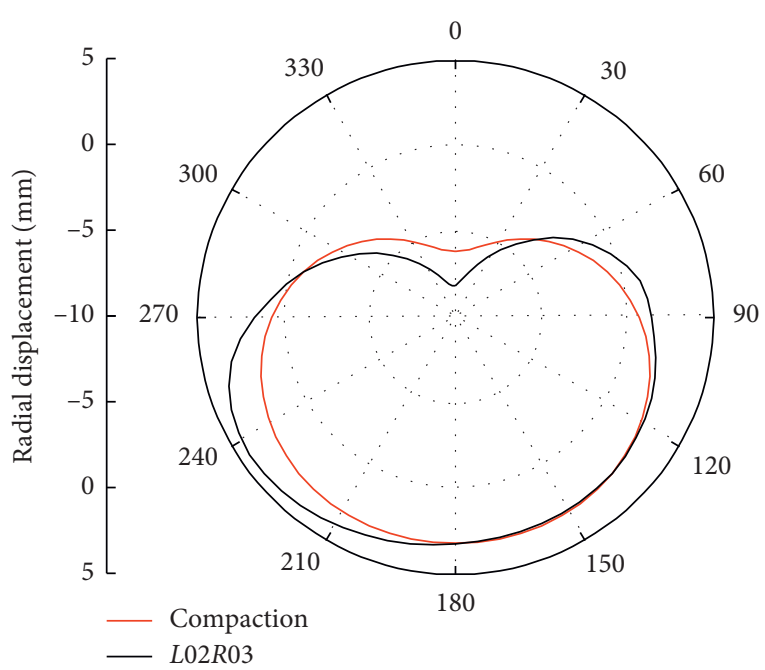

(b)

Figure 19: (a) Circumferential strain distribution. (b) Radial displacement distribution for the $400 \mathrm{~mm}$ pipe when the backfill on the left of layer 02 and right of layer 03 is loose.

TABLE 5: Percentage increment of maximum circumferential strain value for pipes with different nominal diameters under various backfill conditions.

\begin{tabular}{lccccc}
\hline Loose area & $\begin{array}{c}\text { Inside diameter } \\
(\mathrm{mm})\end{array}$ & $\begin{array}{c}\text { Crest } \\
(\%)\end{array}$ & $\begin{array}{c}\text { Valley } \\
(\%)\end{array}$ & $\begin{array}{c}\text { Liner } \\
(\%)\end{array}$ & $\begin{array}{c}\text { The maximum difference between the valley and } \\
\text { liner }(\%)\end{array}$ \\
\hline Left side of Layer 02 & 400 & 59 & 23 & 26 & 16 \\
& 800 & 25 & 28 & 34 & 27 \\
Left side of Layer 03 & 400 & 60 & 20 & 27 & 27 \\
Left of Layer 02 and right of & 800 & 18 & 26 & 33 & 32 \\
Layer 03 & 400 & 77 & 40 & 44 & 36 \\
\hline
\end{tabular}

strain, nearly equal, on the interior walls in this area. The response of crest strain to this backfill condition is more sensitive and complicated. The crest strain value at each position of the pipe increases, and the distribution characteristics of the crest strain, in this case, are different from that under the compaction backfill condition. The minimum point of the crest strain is located at the shoulder of the pipe, and the maximum point appears near the invert of the pipe. Under this backfill condition, the maximum strain values at the crest and the valley of the $400 \mathrm{~mm}$ pipe are nearly equal, while for the $800 \mathrm{~mm}$ pipe, the maximum valley strain is much larger than the maximum crest strain. It shows that the influence of the loose backfill on the valley strain of the largediameter pipes is more significant than on the crest or the liner. However, the presence of loose backfill also causes an increase in the radial displacement of the pipe from the right pipe shoulder to the top of the pipe area and the left side of the pipe.

To further clarify the deformation of small-diameter pipelines under loose backfill conditions, we summarize the maximum strain at the critical positions and the increment of the maximum strain at the interior wall under three backfill conditions for $400 \mathrm{~mm}$ and $800 \mathrm{~mm}$ pipe as tabulated in Table 5. The influence of loose backfill on smalldiameter pipelines is mainly reflected in the crest. In contrast, the liner and valley of the large-diameter pipelines are more susceptible, indicating that the large-diameter pipelines are more likely to be damaged due to local bending of the pipe under loose backfill conditions. In contrast, the small-diameter pipelines may suffer damage due to uneven strain distribution under the same condition.

\section{Conclusion}

A refined 3D finite element model of the pipe-soil interaction of HDPE double-wall corrugated buried pipes has been established to perform pipe-soil interaction analyses for different pipe sizes. The analysis was carried out under different backfill conditions. To verify the analytical results, full-scale tests were also conducted. Based on the analytical and experimental results, the following conclusions can be made: 
(1) When the backfill around the pipe is dense, the pipe liner deformation is constrained by the radial displacement of the valley. The liner strain of a smalldiameter pipeline is tensile, while that of large-diameter pipelines is a compressive strain.

(2) Under the uniform compaction backfill condition, the strain distribution curves for the valley and the crest of the buried pipes with different diameters exhibit somewhat similar characteristics. The circumferential strain value at the critical positions of the pipe is proportional to the nominal diameter of the pipe.

(3) Under the poor backfill conditions, the small-diameter pipeline's crest is most affected, while the large-diameter pipeline's liner is more likely to be affected. It implies that under the poor backfill conditions, small-diameter pipelines are more likely to be damaged due to strain concentration. In contrast, large-diameter pipelines may be damaged due to local bending.

\section{Data Availability}

The data used to support the findings of this study have not been made available because the data also form part of an ongoing study.

\section{Conflicts of Interest}

The authors declare no conflicts of interest.

\section{Acknowledgments}

The authors thank Hindawi for its linguistic assistance during the preparation of this manuscript. This research was funded by the Key Technologies for Comprehensive Improvement of Water Environment in Mature Urban BuiltUp Areas (Grant No. KCJJ2018-10) and the Research and Application Promotion of Key Technologies for Ecological Restoration of Water Environment (Grant No. 2019-ZJKJ01).

\section{References}

[1] E. Faragher, C. D. F. Rogers, and P. R. Fleming, "Laboratory determination of soil stiffness data for buried plastic pipes," Transportation Research Record, vol. 1624, pp. 231-236, 1998.

[2] C. D. F. Rogers and R. Talby, "Use of visual methods to investigate influence of installation procedure on pipe-soil interaction," Transportation Research Record, vol. 1541, no. 1, pp. 76-85, 1996.

[3] L. L. Guan, "Determinants on ring stiffness of HDPE doublewall corrugated pipes," Building Materials Technology and Application, no. 1, pp. 1-3, 2016, in Chinese.

[4] J. S. Kang and T. H Han, "Short-term and long-term behaviors of buried corrugated high-density polyethylene (HDPE) pipes," Composites Part B: Engineering, vol. 40, no. 5, pp. 404-412, 2009.

[5] A. Marston, "The theory of external loads on closed conduits in the light of the latest experiments," Highway Research Board Proceedings, vol. 9, pp. 138-170, 1930.
[6] A. Howard, "Load-deflection field test of 27-inch (675-mm) PVC (polyvinyl chloride) pipe," in Buried Plastic Pipe TechnologyASTM International, Pennsylvania, PA, USA, 1990.

[7] E. Faragher, C. D. F. Rogers, and P. R. Fleming, "Laboratory determination of soil stiffness data for buried plastic pipes," Transportation Research Record, vol. 1624, no. 1, pp. 231-236, 1998.

[8] S. Sargand, "Field verification of structural performance of thermoplastic pipe under deep backfill conditions," NASA STI/Recon Technical Report N, vol. 3, 2002.

[9] F. Wang, Y. J. Du, M. Zhou, and Y. J. Zhang, "Experimental study of the effects produced by a backfilling process on fullscale buried corrugated HDPE pipes in fine-grained soils," Journal of Pipeline Systems Engineering and Practice, vol. 7, no. 1, Article ID 05015001, 2015.

[10] S. M. Tafreshi and O. Khalaj, "Analysis of repeated-load laboratory tests on buried plastic pipes in sand," Soil Dynamics and Earthquake Engineering, vol. 31, no. 1, pp. 1-15, 2011.

[11] M. Zhou, Y. J. Du, Y. J. Zhang et al., "Study on the change characteristics of the arching effect during the construction of buried HDPE pipelines," Chinese Journal of Rock Mechanics and Engineering, vol. 2015, no. 2, pp. 414-424, 2015.

[12] M. Zhou, Y. J. Du, F. Wang, A. Arulrajah, and S. Horpibulsuk, "Earth pressures on the trenched HDPE pipes in fine-grained soils during construction phase: full-scale field trial and finite element modeling," Transportation Geotechnics, vol. 12, pp. 56-69, 2017.

[13] M. Zhou, F. Wang, Y. J. Du et al., "Feasibility study on the use of geosynthetics to reinforce buried HDPE pipes subjected to localized ground subsidence," Transportation Geotechnics, vol. 22, Article ID 100303, 2020.

[14] Q. You, Y. J. Zhang, F. Wang et al., "Field test study on assembly strain distribution law during construction of buried HDPE pipelines," Chinese Journal of Geotechnical Engineering, vol. 36, no. 12, pp. 2282-2290, 2014.

[15] J. S. Kang, S. J. Stuart, and J. S. Davidson, "Analytical evaluation of maximum cover limits for thermoplastic pipes used in highway construction," Structure and Infrastructure Engineering, vol. 9, no. 7, pp. 667-674, 2013.

[16] J. Kang, S. J. Stuart, and J. S. Davidson, “Analytical study of minimum cover required for thermoplastic pipes used in highway construction," Structure and Infrastructure Engineering, vol. 10, no. 3, pp. 316-327, 2014.

[17] M. Zhou, F. Wang, Y. J. Du et al., "Laboratory evaluation of buried high-density polyethylene pipes subjected to localized ground subsidence," Acta Geotechnica, vol. 14, no. 4, pp. 1081-1099, 2019.

[18] M. Zhou, I. D. Moore, and H. Lan, "Experimental study of structural response of lined-corrugated HDPE pipe subjected to normal fault," Journal of Geotechnical and Geoenvironmental Engineering, vol. 145, no. 12, pp. 1-15, 2019.

[19] M. L. Talesnick, H. W. Xia, and I. D. Moore, "Earth pressure measurements on buried HDPE pipe," Geotechnique, vol. 61, pp. 721-732, 2011.

[20] N. U. Terzi, F. Yılmazturk, S. Yıldırım, and H. Kilic, "Experimental investigations of backfill conditions on the performance of high-density polyethelene pipes," Experimental Techniques, vol. 36, pp. 40-49, 2012.

[21] R. W. I. Brachman, I. D. Moore, and S. M. Munro, "Compaction effects on strains within profiled thermoplastic pipes," Geosynthetics International, vol. 15, pp. 72-85, 2008.

[22] Y. E.-A. Mohamedzein and M. Y. Al-Aghbari, "Experimental study of the performance of plastic pipes buried in dune 
sand," International Journal of Geotechnical Engineering, vol. 10, pp. 236-245, 2016.

[23] S. M. Dezfooli, A. Abolmaali, and M. Razavi, "Coupled nonlinear finite-element analysis of soil-steel pipe structure interaction," International Journal of Geomechanics, vol. 15, no. 1, Article ID 04014032, 2015.

[24] M. S. Dezfooli, A. Abolmaali, Y. Park, M. Razavi, and F. Bellaver, "Staged construction modeling of steel pipes buried in controlled low-strength material using 3-D nonlinear finite element analysis," International Journal of Geomechanics, vol. 15, no. 6, Article ID 04014088, 2015.

[25] A. S. Dhar, I. D. Moore, and T. J. McGrath, "Two-dimensional analyses of thermoplastic culvert deformations and strains," Journal of Geotechnical and Geoenvironmental Engineering, vol. 130, no. 2, pp. 199-208, 2004.

[26] D. S. Al-Abri and Y. E. Mohamedzein, "Performance of plastic pipes installed in dune sand," in Pipelines 2010: Climbing New Peaks to Infrastructure Reliability-Renew, pp. 402-414, Rehab, and Reinvest, 2010.

[27] M. A. Noor and A. S. Dhar, "Three-dimensional response of buried pipe under vehicle loads," in Proceedings of the 2003 International Conference Pipeline Engineering and Construction, American Society of Civil Engineers, Baltimore, MA, USA, July 2003.

[28] S. A. Naeini, E. Mahmoudi, M. M. Shojaedin, and M. Misaghian, "Mechanical response of buried High-Density Polyethylene pipes under normal fault motions," KSCE Journal of Civil Engineering, vol. 20, pp. 2253-2261, 2016.

[29] K. Zhai, H. Fang, B. Fu, F. Wang, and B. Hu, "Mechanical response of externally bonded CFRP on repair of PCCPs with broken wires under internal water pressure," Construction and Building Materials, vol. 239, Article ID 117878, 2019.

[30] K. Zhai, H. Fang, C. Guo et al., "Mechanical properties of CFRP-strengthened prestressed concrete cylinder pipe based on multi-field coupling," Thin-Walled Structures, vol. 162, Article ID 107629, 2021.

[31] K. Zhai, H. Fang, C. Guo et al., "Strengthening of PCCP with broken wires using prestressed CFRP," Construction and Building Materials, vol. 267, Article ID 120903, 2021.

[32] H. Fang, P. Tan, X. Du, B. Li, K. Yang, and Y. Zhang, "Numerical and experimental investigation of the effect of traffic load on the mechanical characteristics of HDPE double-wall corrugated pipe," Applied Sciences, vol. 10, no. 2, 2020.

[33] H. Fang, P. Tan, X. Du, K. Yang, and Y. Zhang, "Mechanical response of buried HDPE double-wall corrugated pipe under traffic-sewage coupling load," Tunnelling and Underground Space Technology, vol. 108, Article ID 103664, 2021.

[34] R. D. Peindl, R. Janardhanam, and F. Burns, "Evaluation of flowable fly-ash backfill. I: static loading," Journal of Geotechnical Engineering, vol. 118, pp. 449-463, 1992.

[35] T. Jin, Yield behavior and macroscopic phenomenological constitutive study of semicrystalline polymers, Taiyuan University of Technology, Taiyuan, China, 2016.

[36] L. Xu, G. Gao, Z. Zhao, J. Wang, C. Cheng, and Z. Du, "Compressive mechanical properties of polyethylene materials under different strain rates," Explosion and Shock, vol. 39, no. 01 , pp. 58-65, 2019.

[37] Ministry of Housing and Urban-Rural Development of the People's Republic of China, CJJ143-2010. Technical Specification for Buried Plastic Drainage Pipes Engineering, China Construction Industry Press, Beijing, China, 2010.

[38] Q. Zhu, Y. Liu, L. Jiang, and X. Zhang, "Analysis of the influence of pipe-soil friction and pipe diameter on the destruction of buried pipes," Earthquake Engineering and Engineering Vibration, no. 3, pp. 197-199, 2006.

[39] G. Moradi and A. Abbasnejad, "Experimental and numerical investigation of arching effect in sand using modified Mohr Coulomb," Geomechanics and Engineering, vol. 8, pp. 829844, 2015.

[40] B. Li, H. Fang, K. Yang, P. Tan, and F. Wang, "Dynamic analysis of concrete pipes under the coupled effects of traffic load and groundwater level fluctuations," Energy Science and Engineering, vol. 8, no. 5, 2019.

[41] B. Li, F. Wang, H. Fang, K. Yang, X. Zhang, and Y. Ji, "Experimental and numerical study on polymer grouting pretreatment technology in void and corroded concrete pipes," Tunnelling and Underground Space Technology, Article ID 103842, 2021.

[42] B. Li, X. Guo, H. Fang et al., "Prediction equation for maximum stress of concrete drainage pipelines subjected to various damages and complex service conditions," Construction and Building Materials, vol. 264, Article ID 120238, 2020.

[43] Ministry of Construction of the People's Republic of China, GB503322002.Design Principle of Pipeline Structure of Water Supply and Drainage Engineering, China Construction Industry Press, Beijing, China, 2003.

[44] A Dhar, Limit states of profiled thermoplastic pipes under deep buried, Ph.D. thesis, University of Western Ontario, London, 2002. 